\section{Estágio Supervisionado de Língua Inglesa como espaço de (trans)formação de professores}

Supervised teaching practice in English as a space for the
Cristiane Carvalho de Paula BRITO (UFU) depaulabrito@gmail.com

Fernanda Costa RIBAS (UFU) ribasileel@gmail.com

Recebido em: 16 de maio de 2018. Aceito em: 25 de set. de 2018.
BRITO, Cristiane Carvalho de Paula; RIBAS, Fernanda Costa. Estágio Supervisionado de Língua Inglesa como espaço de (trans)formação de professores. Entrepalavras, Fortaleza, v. 8, n. 3 , p. $244-263$, out-dez/2018

Resumo: Este artigo visa descrever a configuração das disciplinas de estágio supervisionado de língua inglesa, em uma universidade pública mineira, tendo em vista algumas ações e propostas que têm sido (e serão) desenvolvidas na formação dos futuros professores e que buscam articular ensino, pesquisa e extensão. Damos destaque aos resultados do projeto de extensão "Curso de língua inglesa: professores em formação", discutindo contribuições e desafios em seu desenvolvimento, bem como as percepções dos professores em formação acerca da experiência de docência nesse projeto. Fundamentamo-nos nos estudos em Linguística Aplicada que postulam a linguagem como prática social e política (CELANI, 2010; LEFFA, 2001), a fim de discutir os estágios supervisionados como espaços de formação para educadores e licenciandos que possibilitam a revisitação de teorias estudadas e a ressignificação dos processos de ensino-aprendizagem de uma língua outra.

Palavras-chave: Estágio supervisionado. Língua inglesa. Cursos de extensão universitária. 
Abstract: This paper aims at describing the configuration of English supervised teaching practice programs in a public university in the state of Minas Gerais (Brazil), taking into consideration some actions and proposals that have been (and will be) developed in the education of future teachers and that attempt to articulate teaching, research and extension. We focus on the results of the extension project "English Course: teacher education", discussing the contributions and challenges of its development, as well as the preservice teachers' perceptions concerning their experience of teaching in this project. We are based on the studies of Applied Linguistics that posit language as a social and political practice (CELANI, 2010; LEFFA, 2001), in order to discuss the supervised practice as spaces for the development of educators and preservice teachers, which make it possible the revisiting of studied theories and the ressignification of the teaching-learning processes of 'the language of the other.

Keywords: Supervised practice. English language. University extension courses.

\section{Introdução}

O estágio supervisionado no curso de licenciatura em Letras se configura em um importante momento na formação dos futuros professores de línguas e literaturas por possibilitar reflexões em movimentos que vão das teorias para a prática de sala de aula e das práticas para novas teorias. O componente teórico do estágio permite que os graduandos construam, reconstruam e coconstruam teorias estudadas ao longo do curso de Letras nas mais variadas disciplinas, tais como Linguística Aplicada e Metodologias de Ensino de Línguas. O componente prático, por sua vez, possibilita aos futuros professores experienciar e produzir teorizações a partir de vivências em contextos reais de ensino-aprendizagem de línguas. Portanto, o estágio não é apenas um momento de 'aplicação' de teorias à prática, como se a relação entre estas fosse de caráter dicotômico. Trata-se de um espaço de formação e de possíveis deslocamentos discursivos, por promover a revisitação de teorias estudadas pelo licenciando e a ressignificação dos processos de ensino-aprendizagem de uma outra língua.

Tendo em vista a importância do estágio, no presente trabalho, descrevemos como se configura o estágio supervisionado em Língua Inglesa (LI) no curso de Letras da Universidade Federal de Uberlândia, de forma a destacar as ações e propostas que têm sido (e serão) desenvolvidas na formação dos futuros professores, articulando ensino, pesquisa e extensão. Para isso, dividimos este artigo em três seções, além desta introdução e considerações finais. Primeiramente, apresentamos alguns pressupostos teóricos que embasam nosso trabalho como professoras formadoras e supervisoras nas disciplinas de estágio e que respaldam nossa visão acerca da formação de professores 
v. 8 (3)

$244-263$

out-dez

2018

de LI. Em seguida, descrevemos a atual organização das disciplinas de estágio em nosso curso, entrevendo a relação entre os componentes teóricos e práticos. Compartilhamos ainda nossa avaliação do projeto de extensão "Curso de Língua Inglesa: professores em formação", ligado aos estágios supervisionados, apontando suas contribuições para os professores em formação e para a comunidade, além de problematizar as dificuldades e desafios enfrentados em seu desenvolvimento. Também, nessa seção, discutimos algumas percepções dos professores em formação, presentes em seus relatos críticos-reflexivos, acerca da experiência do estágio. Por fim, tendo em vista a necessidade de reformularmos constantemente os cursos de formação de professores de forma a preparar os futuros docentes para as mudanças que ocorrem na sociedade, principalmente devido aos avanços nas tecnologias digitais de informação e comunicação, apresentamos uma proposta de reconfiguração das disciplinas de estágio a partir da mudança curricular do curso de Letras em que atuamos. Com isso, esperamos contribuir para o mapeamento das experiências com os estágios na área de línguas no cenário brasileiro e para o aprofundamento da discussão acerca da formação de professores em tempos de novos letramentos.

\section{Estágio Supervisionado de LI como espaço de (trans)formação na/pela linguagem}

Um dos pilares da formação de professores de línguas sustenta-se, a nosso ver, nas concepções de língua(gem) discutidas, problematizadas e vivenciadas pelos professores em formação ao longo da licenciatura. São essas concepções que, em grande medida, incidem na prática docente, moldando e informando as decisões tomadas acerca do que e como ensinar, da escolha do material didático, das formas de avaliação, dentre outras. Principalmente quando dá oportunidade aos professores em formação para aprenderem de forma experiencial, ligando teoria e prática, o curso de formação permite que os professores superem noções prévias e, às vezes, simplistas, sobre o que significa ensinar e aprender uma língua, as quais são construídas com base em suas próprias experiências enquanto aprendizes de língua (BORG et al., 2014). É pela experiência, segundo Passarelli (2008, p. 227), que os futuros professores constroem os conhecimentos necessários a sua atuação profissional, pois "o adulto retém como saber de referência o que está ligado à sua experiência e à sua identidade". 
Portanto, no curso de formação, o estágio supervisionado, ao aliar componentes teóricos e práticos, se apresenta como um lugar privilegiado para (re)construções de sentido relacionadas às teorias e às experiências de ensino-aprendizagem dos professores em formação, abrindo espaço para estes compartilharem suas compreensões, concordâncias e discordâncias em relação ao próprio discurso e ao discurso dos colegas.

Para o desenvolvimento dos estágios, apoiamo-nos nos estudos em Linguística Aplicada (CELANI, 2010; LEFFA, 2001), que postulam a linguagem como prática ideológica-social e política, sempre situada, a fim de abordar discussões sobre letramentos (MATTOS, 2013; SAITO; SOUZA, 2011), uso de tecnologia nas aulas de LI (WARE; LIAW; WARSCHAUER, 2012; WARSCHAUER; WHITTAKER, 2002), relação linguagem, identidade e poder (URZÊDA-FREITAS, 2012), gêneros textuais (BEATO-CANATO; CRISTOVÃO, 2014; CRISTOVÃO et al., 2010), dentre outros. Esse escopo teórico nos permite pensar os Estágios Supervisionados como momentos de diálogos, de desnaturalização de sentidos cristalizados, de questionamentos acerca da ilusão de completude que comumente atravessa os discursos sobre a prática pedagógica (BRITO, 2012a, 2012b, 2014).

A realidade de ensino contemporânea é caracterizada por mudanças, imprevisibilidade e complexidade. Portanto, os professores precisam ter flexibilidade e sensibilidade para adaptarem-se a diferentes situações e escolherem soluções plausíveis a seus contextos de atuação. Acreditamos, então, que o Estágio Supervisionado deva preparar os professores nesse sentido, deixando de lado o modelo tecnicista de formação que se limitava a oferecer receitas prontas aos professores (MONTEIRO, 2011), a fim de oportunizar uma formação que se pretenda crítica (PESSOA, 2011) e comprometida com a justiça social (MATTOS, 2014). Trata-se, pois, de abrir espaço para que o licenciando problematize a noção de língua(gem), de forma a reconhecer que esta - não sendo nunca mera descrição da realidade ou objeto estático e homogêneo, mas sempre um ato político, de tomada de posicionamento responsivo e responsável em relação ao outro - constitui-se como movência: é na e pela língua (gem $)^{1}$ que os sujeitos vendo(-se) (n)o mundo, identificamse, e (se)dizem de uma forma ou de outra, fazendo, assim, com que sentidos (cristalizados) se movam e que práticas sociais se transformem.

${ }^{1}$ Linguagem aqui é tida como "elemento que medeia os processos de construção de conhecimentos" e a construção identitária do professor de línguas nos cursos de formação (CASTRO, 2009, p. 159). 
v. 8 (3)

$244-263$ out-dez 2018

O papel do professor formador nos estágios não reside, portanto, em apenas apresentar saberes científicos aos professores em formação. Isso porque "ensinar não é transferir conhecimento, mas criar as possibilidades para a sua produção e/ou a sua construção" (STURM, 2008, p. 342). Entendemos que o professor formador é, portanto, responsável por estimular práticas entre os futuros professores a partir de "análises contextualizadas de ensino" (GIMENEZ et al., 2008, p. 304), que privilegiam a reflexão crítica na ação, sobre a ação (SCHÖN, 1983) e sobre concepções de linguagem, de ensino e de aprendizagem que embasam o fazer pedagógico do profissional de línguas (BARCELOS, 2007), propondo tarefas que utilizam a linguagem como ferramenta de mediação (NEGUERUELA-AZAROLA, 2011).

É na/pela interação com os futuros professores que o estágio supervisionado se constitui também como um espaço de formação para os formadores. Concordamos com Sturm (2008, p. 342) quando a autora afirma que "na relação formador/formando, ambos são sujeitos na construção e produção de novos saberes". Sensíveis às mudanças que têm ocorrido na sociedade, os formadores precisam constantemente reformular tanto suas propostas para a condução dos professores em formação, nas disciplinas de estágio, quanto o próprio desenho curricular dos cursos de Licenciatura, os quais precisam reverberar uma noção coesa de formação - ainda que sempre múltipla e heterogênea em todos os seus componentes.

Ou seja, a reflexão crítica que os formadores estimulam entre os professores em formação deve se aplicar também a sua própria prática. Um profissional crítico é aquele que se assume como ser social e histórico, capaz de pensar, se comunicar, interagir, transformar, criar e realizar (STURM, 2008), o que se aplica tanto ao professor em formação quanto ao formador. Perguntas como "até que ponto os conteúdos e as abordagens empregadas nas disciplinas de estágio estão atingindo os professores em formação? As práticas nas disciplinas de estágio não estão sendo encaradas apenas de forma técnica? Até que ponto as disciplinas oferecidas no curso de formação estão preparando o professor de línguas de forma mais global, para atuarem em uma realidade em constante transformação?" podem nortear o processo de reflexão do professor formador e ajudá-lo nas reformulações que se fizerem necessárias nos currículos. Tais questionamentos têm balizado as propostas que desenvolvemos nas disciplinas de estágio e o olhar que lançamos, no âmbito desse trabalho, para a avaliação do projeto de extensão implementado, conforme abordamos na próxima seção. 


\section{Estágios Supervisionados de LI: articulando ensino, pesquisa e extensão}

O Curso de Licenciatura em Letras da Universidade Federal de Uberlândia possui, na habilitação em Inglês e Literaturas de Língua Inglesa, cinco estágios ${ }^{2}$, os quais se iniciam no último ano do curso, sendo dois feitos no primeiro semestre e três no segundo 3 . No Quadro 1, podemos ver a configuração desses componentes curriculares no que diz respeito à distribuição da carga teórica e prática:

Quadro 1. Componentes Curriculares de Estágio Supervisionado.

\begin{tabular}{|l|c|c|c|}
\hline Estágio Supervisionado & Carga Teórica & Carga Prática & Total de Horas \\
\hline $\begin{array}{l}\text { Estágio Supervisionado de Português } \\
\text { como Língua Estrangeira }\end{array}$ & $15 \mathrm{~h}$ & $60 \mathrm{~h}$ & $75 \mathrm{~h}$ \\
\hline $\begin{array}{l}\text { Estágio Supervisionado de Língua } \\
\text { Inglesa 1 }\end{array}$ & $15 \mathrm{~h}$ & $60 \mathrm{~h}$ & $75 \mathrm{~h}$ \\
\hline $\begin{array}{l}\text { Estágio Supervisionado de Língua } \\
\text { Inglesa 2 }\end{array}$ & $30 \mathrm{~h}$ & $60 \mathrm{~h}$ & $90 \mathrm{~h}$ \\
\hline $\begin{array}{l}\text { Estágio Supervisionado de Inglês } \\
\text { para Fins Específicos }\end{array}$ & $15 \mathrm{~h}$ & $60 \mathrm{~h}$ & $75 \mathrm{~h}$ \\
\hline $\begin{array}{l}\text { Estágio Supervisionado de Práticas } \\
\text { em Tradução }\end{array}$ & $30 \mathrm{~h}$ & $60 \mathrm{~h}$ & $90 \mathrm{~h}$ \\
\hline
\end{tabular}

Fonte: as autoras.

Para o escopo deste artigo, focaremos o Estágio Supervisionado de LI 1, o Estágio Supervisionado de LI 2 e o Estágio Supervisionado de Inglês para Fins Específicos, em que temos atuado há algum tempo e aos quais se liga o projeto de extensão "Curso de Língua Inglesa: professores em formação", que vem sendo desenvolvido desde 2009 e cujos resultados avaliamos neste artigo.

A parte teórica dos Estágios Supervisionados de Língua Inglesa 1 e 2 prioriza a discussão e problematização de textos de diferentes vertentes teóricas (por exemplo, letramento crítico, interacionismo sociodiscursivo), referentes à formação de professores, aos processos de ensino-aprendizagem, ao planejamento de aulas, à produção de material

\footnotetext{
${ }^{2}$ Salientamos que todos os estágios são ministrados por docentes alocados no Curso de Letras.

3 O referido curso foi implementado em 2008 e se trata de uma Licenciatura com habilitações nas seguintes línguas e suas respectivas literaturas: língua inglesa, língua francesa, língua espanhola e língua portuguesa. O discente ingressava no Curso de Letras e, após o segundo período, fazia a opção para a habilitação desejada. Em 2018, iniciou-se o Curso de Letras Inglês, sendo, pois, extintas as habilitações.
} 
v. 8 (3)

$244-263$

out-dez

2018

didático, ao uso de tecnologias, à constituição identitária dos sujeitos aluno e professor, à avaliação da aprendizagem, dentre outros. Quanto ao Estágio Supervisionado de Inglês para Fins Específicos, sua parte teórica consiste na discussão de textos referentes ao ensino de inglês para fins acadêmicos e profissionais, incluindo a análise de necessidades, o lugar da gramática nas aulas, as habilidades, gêneros e contextos de ensino para fins específicos, dentre outros. Nos três estágios, as aulas teóricas são organizadas por meio de aulas expositivo-dialogadas, apresentação de seminários e dinâmicas de grupo. As discussões ocorrem também em ambientes virtuais de aprendizagem (Moodle e Edmodo) que são algumas vezes utilizados de forma complementar às aulas presenciais, pensando em oferecer aos futuros professores não apenas teorizações sobre tecnologia, mas experiências reais de uso.

Parte da carga prática desses estágios é realizada por meio de minicursos introdutórios de Língua Inglesa, ministrados pelos professores estagiários, no espaço físico da própria universidade e sob a orientação dos professores supervisores dos estágios supervisionados ${ }^{4}$. Esses minicursos fazem parte do projeto de extensão acima referido, o qual proporciona espaço para o estudo, a reflexão, a discussão e a prática do exercício da docência em inglês, ao mesmo tempo em que atende à demanda da comunidade com necessidade ou interesse de aprender a língua inglesa, quer seja de forma globalizante, quer seja para fins específicos.

Os minicursos têm carga horária de 20 horas e são, geralmente, ministrados em duplas ou trios pelos professores estagiários, visando, assim, a troca de experiências por meio de um trabalho em equipe. As aulas, bem como o material a ser utilizado, são preparados pelos professores estagiários com base nas reflexões teóricas e orientações dos professores responsáveis, os quais também fazem observação das aulas para posterior feedback. Esse feedback é geralmente realizado de forma coletiva em que o professor formador, a partir do que foi observado nas aulas, propõe aos professores em formação a (re)discussão de pontos teóricos que se façam necessários para o aprofundamento da reflexão desses sobre sua prática de sala de aula. Também há momentos em que a observação de aulas dos colegas (peer observation) é estimulada entre os professores em formação, com o objetivo de desencadear reflexões acerca de seu próprio ensino, bem como promover o compartilhamento de preocupações, problemas e ideias suscitados durante as regências, em sessões reflexivas com o grupo.

4 Nos Estágios Supervisionados de Língua Inglesa 1 e 2, parte da carga prática é realizada por meio da observação e regência em escolas públicas. 
No Quadro 2, podemos ver algumas propostas dos minicursos que vêm sendo oferecidos à comunidade 5 .

Quadro 2. Minicursos de LI oferecidos à comunidade.

\begin{tabular}{|c|c|}
\hline Minicursos oferecidos & Proposta feita pelos professores estagiários \\
\hline $\begin{array}{l}\text { Luz, câmera e ação: } \\
\text { cinema e literatura no } \\
\text { ensino de língua inglesa }\end{array}$ & $\begin{array}{l}\text { Esse minicurso pretende trabalhar o ensino de Língua } \\
\text { Inglesa, a partir de elementos de suporte como a Literatura } \\
\text { e o Cinema. Com essa temática, pretende-se o entrelace de } \\
\text { textos literários escritos, textos literários orais (audiobooks), } \\
\text { excertos defilmes, entrevistas ou documentários, reportagens, } \\
\text { biografias, entre outros, de forma a auxiliarem no ensino de } \\
\text { Língua Inglesa e culturas dessa língua. O minicurso contará } \\
\text { com aulas diversas e dinâmicas, contemplando um espaço } \\
\text { de ensino e aprendizagem de Língua Inglesa. }\end{array}$ \\
\hline $\begin{array}{l}\text { Aprendendo inglês através } \\
\text { do cinema }\end{array}$ & $\begin{array}{l}\text { Este minicurso é focado no ensino da língua inglesa por meio } \\
\text { das situações comunicativas abordadas em segmentos de } \\
\text { filmes e/ou de séries de televisão. Os aspectos gramaticais e } \\
\text { comunicativos da língua alvo serão trabalhados a partir do modo } \\
\text { como são utilizados nos segmentos retirados de filmes/séries } \\
\text { em língua inglesa, abrindo caminho para explorar os usos de tais } \\
\text { aspectos, não só como aparecem nos segmentos trabalhados, } \\
\text { mas também em outras possíveis situações de comunicação. } \\
\text { curso se destina a alunos do nível básico de todas as idades. }\end{array}$ \\
\hline $\begin{array}{l}\text { Aprendendo inglês por } \\
\text { meio de vídeos }\end{array}$ & $\begin{array}{l}\text { Um dos principais desafios no ensino de uma língua estrangeira } \\
\text { é conseguir aproximar o aluno da maneira como o idioma é } \\
\text { efetivamente usado no dia a dia. Por isso, este minicurso visa } \\
\text { ensinar a língua inglesa por meio de vídeos, recortes de filmes, } \\
\text { seriados, programas de TV, desenhos animados etc. Dessa } \\
\text { forma, pretendemos aproximar este minicurso da realidade } \\
\text { dos estudantes, já que estão diariamente expostos a programas } \\
\text { de televisão, filmes estrangeiros etc. As aulas contarão com } \\
\text { discussões de temas atuais, como meio ambiente, viagens, } \\
\text { entre outros, e também serão trabalhados aspectos da língua } \\
\text { como gramática, vocabulário, gírias, e outras peculiaridades. } \\
\text { Venha aprender inglês de uma forma divertida e diferente! }\end{array}$ \\
\hline $\begin{array}{l}\text { Cinquenta tons de inglês: } \\
\text { inglês em diferentes } \\
\text { contextos }\end{array}$ & $\begin{array}{l}\text { O objetivo desse minicurso é apresentar e refletir sobre a } \\
\text { configuração do inglês em diferentes contextos. Apesar de } \\
\text { grande parte da língua inglesa estar voltada para a comunicação } \\
\text { oral e escrita, isso não significa que a língua esteja limitada } \\
\text { apenas a esses fins. Pretendemos, então, apresentar contextos } \\
\text { variados, pensando nas diferenças entre os usos da língua } \\
\text { inglesa, como músicas, jogos eletrônicos, propagandas, } \\
\text { poemas, jornais etc. Ao refletir sobre esses contextos, nosso } \\
\text { objetivo é proporcionar ao aluno uma chance de refletir sobre } \\
\text { sua própria língua e sobre o uso da língua em seus mais } \\
\text { variados campos. }\end{array}$ \\
\hline
\end{tabular}

\footnotetext{
5 Os minicursos foram formalizados como projetos de extensão em 2009. Todavia, já aconteciam informalmente há mais tempo na instituição.
} 
v. 8 (3)

$244-263$

out-dez

2018

\begin{tabular}{|l|l|}
\hline $\begin{array}{l}\text { Aprendendo inglês com } \\
\text { música }\end{array}$ & $\begin{array}{l}\text { Oferecemos um minicurso de inglês para quem quer aprender } \\
\text { língua estrangeira de um jeito diferente: trabalhando com } \\
\text { músicas. A partir de variadas músicas, trabalharemos a } \\
\text { compreensão e produção oral e escrita na língua inglesa, } \\
\text { bem como aspectos gramaticais e culturais. }\end{array}$ \\
\hline Voando com seu inglês & $\begin{array}{l}\text { Com ênfase no uso da língua inglesa no contexto de viagens, } \\
\text { este curso visa a prática e o ensino de habilidades que vão } \\
\text { capacitar o aluno a se comunicar em situações de intercâmbio } \\
\text { e/ou viagens turísticas. Serão trabalhadas situações como: } \\
\text { tirando dúvidas no aeroporto, entrevista na imigração, pedindo } \\
\text { direções e entendendo as linhas telefônicas estrangeiras. }\end{array}$ \\
\hline Inglês para músicos & $\begin{array}{l}\text { Este minicurso tem como objetivo identificar e estudar } \\
\text { elementos da língua inglesa presentes em textos da área de } \\
\text { Música. Pretende-se investigar elementos linguísticos mais } \\
\text { frequentes em partituras e apostilas de teoria musical, para } \\
\text { que os alunos sejam capazes de utilizar a língua inglesa para } \\
\text { refletir sobre sua área por outra perspectiva. }\end{array}$ \\
\hline $\begin{array}{l}\text { Estratégias de leitura } \\
\text { para iniciantes para fins } \\
\text { profissionais }\end{array}$ & $\begin{array}{l}\text { Este minicurso tem como objetivo trabalhar estratégias de } \\
\text { leitura com ênfase em gêneros textuais ligados a situações de } \\
\text { trabalho (por exemplo, anúncio de emprego, ficha de emprego, } \\
\text { curriculum, e-mail, memorando, aviso, relatório, dentre outros). }\end{array}$ \\
\hline
\end{tabular}

Fonte: as autoras.

Os temas elencados para os minicursos são direcionados a partir das reflexões feitas na parte teórica das disciplinas de estágio. Os professores em formação são orientados a elaborar propostas de cursos que se fundamentem em visões sociointeracionistas de linguagem, de forma a priorizar um ensino que permita, aos aprendizes, possibilidades de: (se)dizerem na língua alvo; interagirem em diferentes contextos comunicativos; problematizarem sentidos cristalizados e hegemônicos em textos verbo-visuais orais e escritos; desenvolverem a autonomia e colaboração na aprendizagem; experienciarem a aprendizagem de uma língua estrangeira com o apoio de recursos digitais etc. Enfim, trata-se de delinear propostas que se desloquem de um ensino predominantemente gramatical e voltado para aquisição de itens lexicais, prática muito recorrente no ensino de LI (CELANI, 2010), para ensejar um ensino socialmente relevante (KUMARAVADIVELU, 2003).

Com base na ministração dos minicursos, os alunos devem produzir um relato crítico-reflexivo acerca da experiência vivenciada. Esse relato compõe uma das partes do relatório final a ser entregue na disciplina de Estágio Supervisionado, o qual, por sua vez, se configura como o principal instrumento de avaliação pelo formador. Para a elaboração dessa reflexão escrita, os professores em formação são orientados a observar aspectos como: contextualização e descrição das atividades realizadas no estágio, posicionamento sobre os fatos 
ocorridos na sala de aula, confronto entre o planejamento e a aula dada, articulação entre a prática e as teorias estudadas ao longo do Curso de Letras, apresentação de sugestões, dentre outros.

A nosso ver, a produção do relato crítico-reflexivo se constitui em um importante momento da formação, especialmente se considerarmos que "a escrita pode permitir a emergência de deslocamentos significativos - e significantes - aos sujeitos, promovendo sua inscrição em outras formações discursivas e o questionamento de discursos cristalizados" (BRITO, 2014, p. 294). Não se trata, pois, de meramente descrever as ações realizadas nas aulas, mas de lançar um olhar para a prática, já de um outro lugar: o do pesquisador e não apenas o de professor. Isto é, a reflexão da prática pedagógica, por meio da escrita, visa encorajar o licenciando a questionar sua experiência, a darlhe um 'caráter de unidade', a costurar uma narrativa sobre si e sobre os outros que problematize seu lugar como professor em formação, o que pode incidir em seu desenvolvimento profissional. Incentivamos, assim, uma postura de pesquisador permanente, que esperamos que os professores em formação carreguem consigo ao longo de suas trajetórias profissionais.

A atividade investigativa na formação inicial, como postula Cárdenas (2008, p. 47), figura como uma ferramenta que possibilita "ir mais além da transmissão de conhecimentos e construir explicações". Ela transforma o ensino, pois permite teorizações, articulações de intenções, avaliações de suposições e conexões com a prática (CÁRDENAS, 2008). Atuando como pesquisadores, os professores em formação, em vez de serem meros consumidores de conhecimento produzido por outros pesquisadores, se tornam agentes, ou seja, produtores de sentidos e de teorizações sobre os eventos que ocorrem em suas aulas. Trata-se, pois, de contemplar o que Kumaravadivelu (2001) denomina de pedagogia da praticidade, a qual visa refutar a concepção de professor como mero aplicador de teorias produzidas por especialistas, a fim de valorizá-lo como produtor de conhecimento, a partir de seu locus de atuação.

Avaliação do projeto de extensão: contribuições e desafios

Como postula Castro (2009), cada vez mais, o contexto universitário se institui como um espaço em que pesquisa e ensino se articulam a ações voltadas para a comunidade, fazendo com que a universidade possa exercer melhor sua missão. A extensão traz 
v. 8 (3)

$244-263$

out-dez 2018

contribuições tanto para a comunidade atendida pelas ações quanto para os universitários executores das propostas. Para Garcia (2012, p. 45):

A extensão universitária, a partir da socialização do conhecimento e da inserção comunitária, pode ser um canal privilegiado para o exercício em direção à práxis, que, definitivamente, precisa ser compreendida como processo imprescindível para que se desfaça a dicotomia entre teoria e prática.

Para a avaliação do projeto, contamos com: notas de campo feitas pelas professoras formadoras, questionários aplicados aos professores em formação e aos alunos participantes dos minicursos de língua inglesa; e relatos críticos-reflexivos produzidos pelos professores em formação. Para o escopo desse trabalho, discutiremos nossas percepções a partir da análise desses instrumentos, destacando as contribuições do projeto "Curso de língua inglesa: professores em formação" tanto para comunidade quanto para a formação dos professores, e também alguns desafios.

Em relação às contribuições do projeto para a comunidade, podemos destacar:

(i) a oportunidade de ter acesso a conhecimentos básicos na LI. Pela sua duração, pode-se dizer que os cursos cumprem o papel de despertar o aluno para a aprendizagem de uma LE e de propiciar, para os que já têm algum conhecimento, um maior contato com a língua;

(ii) a oportunidade de experienciar formas de aprender a língua inglesa que fogem ao tradicional. As aulas dos minicursos preparadas pelos professores em formação não seguem o tradicional sequenciamento linear de estruturas linguísticas comumente vistas nos livros didáticos. O trabalho com gêneros discursivos que circulam na atualidade e com o letramento crítico costuma permear a execução das aulas;

(iii) a oportunidade de desenvolver o letramento digital na aprendizagem de uma língua estrangeira. Experiências com ferramentas digitais promovidas pelos professores em formação durante as aulas (por exemplo, interações via email ou via ambiente virtual de aprendizagem) podem contribuir para que os participantes dos minicursos 
"identifiquem, acessem, administrem, integrem, avaliem, analisem e sintetizem recursos digitais", tendo um olhar crítico perante as tecnologias (MARTIN, 2008, p. 167);

(iv) a oportunidade de inserção na universidade. Os minicursos trazem a comunidade para 'dentro da universidade', representando, para muitos alunos, especialmente os adolescentes provenientes da escola pública, a possibilidade de conhecer a universidade pela primeira vez, o que pode gerar (ou consolidar) o interesse de ingressar na instituição.

Quanto às contribuições do projeto para os professores em formação, é preciso salientar:

(i) o estabelecimento de campo para o estágio, amenizando a falta de uma política de estágio nas licenciaturas. O desenvolvimento do estágio fica, em geral, a critério dos professores supervisores e conta com a colaboração de escolas na cidade. Contudo, não é incomum encontrar resistência por parte de professores da escola básica em aceitarem a presença de estagiários em suas aulas;

(ii) a experiência significativa de regência e reflexão sobre cursos de LI para fins gerais e específicos, desde a escolha do tema a ser dado, passando pela elaboração do planejamento e, por fim, a docência. Os minicursos demandam do professor em formação que se comprometa com 'sua' turma, e se responsabilize por todas as etapas do ensino;

(iii) a sensibilização quanto à importância de se lidar com a heterogeneidade e necessidades dos alunos - tanto no curso geral quanto específico. Uma vez que a turma não está estabelecida a priori (como acontece com a regência na escola regular) e está aberta para um público bastante heterogêneo, é preciso planejar - e replanejar - as aulas conforme às necessidades e características de cada grupo;

(iv) a possibilidade de reflexão quanto ao uso da tecnologia nas aulas de LI (cuidado com seu objetivo e sua operacionalidade, aprender a utilizar a tecnologia a favor do conhecimento); 
V. 8 (3)

$244-263$

out-dez

2018

(v) a preparação "intelectual e psicológica" dos alunosprofessores para lecionar - já que para muitos o estágio se constitui como uma das primeiras experiências de regência, propriamente ditas;

(vi) a possibilidade de maior acompanhamento de todo o processo de estágio pelo professor supervisor, desde a preparação de aulas e material didático até a ministração das aulas, propriamente ditas, uma vez que essas ocorrem no câmpus da universidade.

Ao serem solicitados a falar sobre suas percepções acerca da experiência de regência nos minicursos, os professores em formação ressaltam em seus relatos crítico-reflexivos ${ }^{6}$ aspectos como: as dificuldades do trabalho em grupo, a necessidade de pesquisa para elaborar e ministrar as aulas, a importância da reflexão sobre a prática, os desafios do uso da tecnologia em sala de aula, dentre outros. No Quadro 3 abaixo, reproduzimos alguns de seus posicionamentos.

Quadro 3. Depoimentos de professores em formação sobre experiência nos minicursos.

Vejo como pontos positivos a carga teórica, a possibilidade de discussão desta teoria em sala de aula com os colegas antes de partir para a parte prática da disciplina. A questão do trabalho em grupo se torna um desafio já que temos que lidar com as diferenças, dividir experiências, compartilhar conhecimento e ter abertura para procurar orientação sempre que necessário. $\left(\mathrm{P}^{1}{ }^{1}\right)$

A regência foi difícil, mas foi, na mesma medida, gratificante, além de provocar reflexões sobre o meu comportamento como professor de Língua Inglesa". (P2)

Nesta disciplina, aprendi mais e explorei mais sobre o ESP, e para a elaboração das aulas tive que estudar e pesquisar sobre leitura instrumental e como ensiná-la" (P3)

A participação na plataforma durante as minhas aulas aconteceu apenas por quatro de 10 alunos presentes. Uma das razões que pode ter acarretado isso foi a resistência com as novas tecnologias ou até mesmo medo. Ao perceber a baixa participação dos alunos no Edmodo e a dificuldade de alguns em postar as atividades, eu deixei que eles me mandassem as atividades por e-mail ou as levassem na aula" (P4)

Referente a colaboração professor- aluno e aluno-aluno pouco ocorreu na plataforma, afinal a maioria dos posts de tarefas e etc eram diretos, alguns abertos inicialmente, porém sem a intervenção de um colega ou comentários sobre o que tinha sido apresentado pelo outro. Acho que faltaram uns chats e outros tipos de atividades na plataforma que estimulassem o trabalho de cooperação ou em grupos e fizesse com que os alunos se integrassem mais, buscassem resolver tais desafios ou tarefas em conjunto com a orientação e participação do professor" (P5)

Fonte: as autoras.

${ }^{6}$ Os relatos crítico-reflexivos sobre os minicursos são entregues ao final dos estágios como parte avaliativa do relatório final. Os depoimentos do Quadro 3 foram coletados em 2013. 
Enquanto professoras formadoras e supervisoras de estágio, concordamos com P1 quando este aponta o trabalho em equipe como um desafio no estágio. Nosso desejo é que os professores em formação desenvolvam um trabalho colaborativo no planejamento e ministração dos minicursos, ainda mais em tempos de novos letramentos que focalizam "o compartilhamento de conhecimentos (e não sua centralização), a inteligência coletiva e a colaboração" (COSTA; REATEGUI, 2012, p. 841). Hoje se pode contar com tecnologias digitais que podem auxiliar enormemente a comunicação e a negociação de sentidos entre os professores em formação. Ao contrário da cooperação em que há troca de ideias e divisão de responsabilidades que se encerram no momento do término de uma tarefa (LEFFA, 2017), a colaboração entre os professores permite revisões, remixagens e transformações nos planos, materiais e atividades produzidos para as aulas de maneira coletiva. É uma prática, assim, desejada, mas também difícil de ser executada, pois requer mobilização de esforços e negociações constantes entre os professores.

Outro ponto que chama nossa atenção nos depoimentos são os comentários de $\mathrm{P}_{4}$ e $\mathrm{P} 5$ sobre o trabalho que desenvolveram com seus alunos em um dos minicursos, o qual envolveu a ministração de algumas aulas a distância, por meio da Plataforma Edmodo. Ambos os professores avaliam negativamente a participação dos alunos da comunidade na referida plataforma, que não atendeu as suas expectativas. Vemos que os alunosparticipantes levam para o ambiente virtual posturas típicas de uma cultura escolar mais tradicional, baseada no individualismo e "no papel e lápis".

Essas constatações realizadas pelos professores em formação sobre as aulas do projeto nos mostram que a reflexão na ação, proporcionada pela experiência de reger uma aula, e sobre a ação (SCHÖN, 1983)7, desencadeada, por exemplo, nos momentos de preparação de aulas e escrita do relatório, bem como a reflexão sobre concepções de linguagem, de ensinar e de aprender são caminhos que podem motivar os futuros professores a considerar ideias alternativas e modos diferentes de pensar sobre determinado aspecto do ensino e aprendizagem (BARCELOS, 2007). A reflexão sobre a ação é percebida nos depoimentos de P2 quando este cita a oportunidade de rever seus comportamentos nas aulas durante as regências e de $\mathrm{P} 4$ quando este comenta sobre decisões que tomou ao perceber problemas na participação e desempenho dos alunos nas atividades desenvolvidas a distância (via Edmodo).

\footnotetext{
7 Para Schon (1983), a reflexão na ação consiste em julgamentos e decisões que os professores tomam a todo o instante em suas aulas, ou seja, enquanto estão ensinando. Já a reflexão sobre a ação se dá antes e depois das aulas, por exemplo, nos momentos de preparação de aulas e de correção de tarefas dos alunos.
} 
v. 8 (3)

$244-263$

out-dez

2018

Como nos lembra Silva (2011, p. 45), os professores "podem não ter consciência das teorias informais que os guiam em sala de aula e, ao mesmo tempo, quais são suas implicações para o processo de ensino-aprendizagem de línguas". Portanto, a reflexão, como defendem Araújo, Alencar e Oliveira (2013), deve ser um trabalho constante do professor, cuja meta não deve se restringir ao encontro de respostas. É a busca por respostas, na visão dos autores, que se torna emancipatória. Permite que o professor compreenda seu fazer e não só reproduza o que lhe foi ensinado nos cursos de formação. Nessa tarefa reflexiva, suscitada pela escrita dos relatos críticos-reflexivos e pelas discussões em grupo, a linguagem apresenta papel fundamental como mediadora na (re) construção de sentidos. Por meio da linguagem, os professores podem conectar suas concepções baseadas em suas histórias pessoais com ideias que leram em publicações científicas (teorias), contrastando-as com as práticas pedagógicas concretizadas nos minicursos (NEGUERUELA-AZAROLA, 2011).

No que diz respeito aos desafios e dificuldades que encontramos para o desenvolvimento do projeto dos minicursos, podemos mencionar tanto questões práticas quanto aspectos teórico-metodológicos relativos ao ensinoaprendizagem da LI, propriamente dito, tais como: (i) o oferecimento de turmas condicionado ao número de estagiários matriculados e à consonância entre o calendário acadêmico da universidade e o da escola básica; (ii) a grande ocorrência de evasão dos alunos matriculados nos minicursos (muitos alunos se matriculam e não comparecem já na primeira semana); (iii) a necessidade de problematizar concepções mais tradicionais sobre ensinar-aprender línguas, o que eventualmente pode levar à desmotivação dos estagiários, quando, por exemplo, ocorre um choque entre suas expectativas e os objetivos e abordagens propostas nos minicursos; e (iv) a preparação dos professores em formação para o ensino de línguas numa era de novos letramentos, principalmente digitais.

Passamos agora à discussão da atual configuração dos estágios, após a reforma curricular feita no curso de Letras em questão.

\section{Reformulação curricular e reconfiguração dos estágios}

O Curso de Letras em questão passou por uma recente reforma curricular na qual as suas várias habilitações foram desmembradas em cursos independentes. A partir de 2018, portanto, o discente ingressa no Curso de Licenciatura Plena em Letras Inglês e Literaturas de Língua Inglesa ${ }^{8}$. No novo Projeto Pedagógico do Curso, configuram-se quatro estágios, conforme se observa no Quadro 4: 
Quadro 4. Componentes Curriculares de Estágio Supervisionado no atual Projeto Pedagógico do Curso de Letras Inglês.

\section{Estágio Supervisionado}

Estágio Supervisionado de Língua Inglesa 1

Estágio Supervisionado de Língua Inglesa 2

Estágio Supervisionado de Língua Inglesa 3

Estágio Supervisionado de Língua Inglesa 4 Fonte: as autoras.

\section{Carga Teórica}

$15 h$

$15 \mathrm{~h}$

$15 \mathrm{~h}$

$15 \mathrm{~h}$

\section{Carga Prática}

9oh

9oh

9oh

9oh
Total de Horas

$105 \mathrm{~h}$

$105 \mathrm{~h}$

$105 \mathrm{~h}$

$105 \mathrm{~h}$

Conforme se observa no Quadro 4, houve um aumento das horas práticas, em todos os estágios, e diminuição da carga teórica em alguns. A diminuição da carga teórica oconreu por duas razões: a) por se entender que disciplinas como Linguística Aplicada, metodologia de ensino, análise e produção de materiais didáticos já contemplam conteúdo teórico que permitem preparar o futuro professor para a realização de atividades práticas exigidas nos estágios e b) para dar maior ênfase às atividades de cunho prático e, assim, permitir maior tempo de elaboração e reflexão por parte dos futuros professores. Desse modo, a parte teórica do estágio fica configurada com o intuito de possibilitar encontros presenciais com os professores em formação para retomada de algumas discussões feitas ao longo do curso de Letras, bem como direcionamento acerca das bases teórico-pedagógicas nas quais a experiência de regência e observação de aulas se fundamentará.

No Quadro 5, ressaltamos os objetivos gerais de cada estágio, tais como explicitados nas fichas de componentes curriculares:

Quadro 5. Objetivos dos Componentes Curriculares de Estágio Supervisionado no atual Projeto Pedagógico do Curso de Letras Ingles.

\section{Estágio}

Estágio Supervisionado de Língua Inglesa 1

Estágio Supervisionado de Língua Inglesa 2

Estágio Supervisionado de Língua Inglesa 3

Estágio Supervisionado de Língua Inglesa 4

Fonte: as autoras.

\section{Objetivos}

Desenvolver observação e prática de ensino de língua inglesa, preferencialmente no Ensino Fundamental, por meio da realização de projetos de pesquisa colaborativa entre a Universidade e a escola regular.

Desenvolver observação e prática de ensino de língua inglesa, preferencialmente no Ensino Médio, por meio da realização de projetos de pesquisa colaborativa entre a Universidade e a escola regular.

Desenvolver cursos e/ou oficinas de ensino de língua inglesa para a comunidade, a partir do levantamento de interesses e necessidades.

Desenvolver cursos e/ou oficinas de ensino de língua inglesa para a comunidade, na modalidade a distância ou semipresencial, a partir do levantamento de interesses e necessidades. 
V. 8 (3)

$244-263$

out-dez

2018

A análise dos objetivos gerais dos estágios nos sugere que a configuração desses componentes curriculares no novo Projeto Pedagógico do Curso de Letras parece pautar-se pela necessidade de: (a) contemplar a diversidade de atuação do professor de LI, permitindolhe experienciar os processos de ensino-aprendizagem em diversos contextos (presenciais e a distância) e com diferentes propósitos; (b) oferecer flexibilidade, ao professor-orientador de estágio, para o desenvolvimento de um trabalho autônomo (como se nota no uso dos advérbios 'preferencialmente' e na proposta do oferecimento de minicursos e oficinas bastante abertas); (c) valorizar a inserção e atuação do licenciando na escola regular (pública), ressaltando, dessa forma, o posicionamento político e o compromisso social do ensino superior gratuito e de qualidade; (d) preparar o aluno para o ensinoaprendizagem de LI na contemporaneidade, oferecendo a oportunidade de estágio na modalidade a distância.

A esse respeito, cumpre salientar que há, no fluxo curricular, disciplinas EaD voltadas para o ensino-aprendizagem de LI, ao longo de todo o curso, com vistas a não apenas promover a discussão teórica sobre o assunto, mas também a propiciar a experiência do estudo no ambiente virtual, com suas especificidades e singularidades. As disciplinas que constituem o novo curso são: Inglês para fins específicos: leitura (EaD); LI: Tradução (EaD); Língua Inglesa: Compreensão e Produção Escrita; Estudos dos Letramentos (EaD); Ensino de Língua Inglesa e as Tecnologias Digitais (presencial). Desse modo, o currículo novo, ao mesmo tempo em que se mostra sensível às demandas da contemporaneidade, também permite a continuação de ações e propostas historicamente consolidadas no Curso de Letras em questão, como é o caso do desenvolvimento de propostas de extensão na universidade como o "Curso de Língua Inglesa: professores em formação".

Vemos as reformulações nos estágios supervisionados anteriormente descritas como medidas que podem enriquecer a formação do futuro professor de língua inglesa por oferecer flexibilidade e variedade de campos de atuação, bem como maior espaço e tempo para o processo de reflexão crítica ocorrer, superando, assim, lacunas que vínhamos experienciando em nosso Curso de Letras. 


\section{Considerações Finais}

A discussão da configuração das disciplinas de Estágio Supervisionado de LI, além de contribuir para a compreensão das diversas práticas implementadas nos cursos de licenciatura em nosso país, também acena para a necessidade de elaboração de políticas educacionais voltadas para os estágios nesses contextos. Políticas essas que sejam sensíveis às especificidades do estágio docente, o qual demanda o acompanhamento e orientação do professor formador (e, portanto, a valorização do professor responsável por esses componentes curriculares no Ensino Superior); o estabelecimento de campos institucionalizados para o estágio (o que significa a existência de parcerias entre a escola e a universidade que efetivamente estejam abertas para receber os licenciandos e que também valorizem o professor da escola pública como um supervisor de estágio); e, finalmente, a valorização da própria licenciatura, não apenas com a criação de programas governamentais, mas principalmente com sólidos investimentos na área da educação.

\section{Referências}

ARAÚJO, A.G.; ALENCAR, T.A.; OLIVEIRA, A.C. Contribuições do trabalho colaborativo e da prática reflexiva para a formação inicial do professor de língua estrangeira. In: DUTRA, D.P.; MELLO, H.R. (Org.). Educação continuada: diálogos entre ensino, pesquisa e extensão. Campinas: Pontes Editores, 2013, p. 261-277.

BARCELOS, A.M.F. Reflexões acerca da mudança de crenças sobre ensino e aprendizagem de línguas. Revista Brasileira de Linguística Aplicada, v. 7, n. 2, p. 109-138, 2007.

BEATO-CANATO, A. P. M.; CRISTOVÃO, V. L. L. Compreensão e produção escrita na perspectiva do interacionismo sociodiscursivo. In: NASCIMENTO, E. L.; ROJO, R. H. R. Gêneros de texto/discurso e os desafios da contemporaneidade. Campinas, SP: Pontes Editores, 2014. p. 57-78.

BORG, S. et al. The impact of teacher education on pre-service primary English language teachers. London: British Council, 2014.

BRITO, C. C. P. Representações discursivas do 'evento-aula': escrita e avaliação no estágio supervisionado de língua inglesa. Calidoscópio, v. 12, n. 3, p. 287295, set/dez 2014.

BRITO, C. C. P. Diários reflexivos de professores de língua inglesa em formação inicial: o outro que (me) confessa. In: SILVA, W. R., SILVA (ed.). Letramento do professor em formação inicial: interdisciplinaridade no estágio supervisionado da licenciatura. Campinas, Pontes Editores, 2012a. p. $139-163$. 
V. 8 (3)

$244-263$ out-dez 2018

BRITO, C. C. P. Entretecendo vozes na (re)escrita de diários reflexivos de professores de línguas em formação inicial. Signum. Estudos de Linguagem, v. 15, n. 2, p. 65-83, 2012 b.

CÁRDENAS, M.L. Un nuevo reto del formador: el asumir el papel de docente investigador. In: GIL, G.; VIEIRA-ABRAHÃO, M.H. (Org.). Educação de professores de línguas: os desafios do formador. Campinas: Pontes, 2008, p. 45-59.

CASTRO, S. T. R. O projeto aprendendo e ensinando línguas: construindo a relação com a teoria na prática de futuros professores de línguas. In: TELLES, J. A. (Org.). Formação inicial e continuada de professores de línguas: dimensões e ações na pesquisa e na prática. Campinas: Pontes, 2009, p. 155-165.

CELANI, M. A. A. Concepção de linguagem de professores de inglês e suas práticas em sala de aula. In:_ (Org.). Reflexões e ações (trans) formadoras no ensino-aprendizagem de inglês. Campinas, SP: Mercado de Letras, 2010. p. 129-140.

COSTA, P. S. C.; REATEGUI, E.B. Oportunidades de letramento através de mineração textual e produção de Fanfictions. Revista Brasileira de Linguística Aplicada, V. 12, n.4, p. 835-859, 2012.

CRISTOVÃO, V. L. L. et al. Uma proposta de planejamento de ensino de língua inglesa em torno de gêneros textuais. Letras, v. 20, n. 40, 2010. p. 191-215.

GARCIA, B.R.Z. A contribuição da extensão universitária para a formação docente. 2012. Tese (Doutorado em Educação) - Pontifícia Universidade Católica de São Paulo, São Paulo, 2012.

GIMENEZ, T.; CRISTÓVÃO, V. L. L.; FURTOSO, V. B.; SANTANA, I. A pesquisa participativa no desenvolvimento profissional de formadores de professores de inglês. In: GIL, G.; VIEIRA-ABRAHÃO, M.H. (org.). Educação de professores de línguas: os desafios do formador. Campinas: Pontes Editores, 2008, p. 303-317.

KUMARAVADIVELU, B. Ensuring Social Relevance. In: Beyond Methods: macrostrategies for Language Teaching. New Heaven: Yale University Press, 2003. p. 239-266.

KUMARAVADIVELU, B. Toward a Postmethod Pedagogy. TESOL QUARTERLY, V. 35, n. ${ }^{\circ} 4$, 2001. p. 537-560.

LEFFA, V. J. Aspectos políticos da formação do professor de línguas estrangeiras. In: LEFFA, V. J. (Org.). 0 professor de línguas estrangeiras: construindo a profissão. Pelotas, 2001, v. 1, p. 333-355.

LEFFA, V. J. Produção de materiais para o enșino de línguas na perspectiva do design crítico. In: TAKAKI, N.; MONTE MÓR, W. (Org.). Construções de sentido e letramento digital crítico na área de línguas/linguagens. Campinas: Pontes, 2017, p. 243-265.

MARTIN, A. Digital literacy and the "digital society". In: LANKSHEAR, C.; KNOBEL, M. (ed.). Digital literacies: concepts, policies and practices. New York: Peter Lang Publishing, 2008, p. 151-176. 
MATTOS, A. M. A. Educating Language Teachers for Social Justice Teaching. Interfaces Brasil/Canadá. Canoas, V. 14, n. 2, 2014, p. 125-151.

MATTOS, A. M. A. Letramento crítico na escola pública: uma experiência de formação continuada de professores de inglês como língua estrangeira. In: DUTRA, D. P.; MELLO, H. R. Educação continuada: diálogos entre ensino, pesquisa e extensão. Campinas: Pontes Editores, 2013, p. 21-76.

MONTEIRO, D. C. Formando professores de EFL: uma reflexão sobre as décadas de 80 e 90. In: SILVA, K. A. da et al. (Org.). A formação de professores de línguas: novos olhares - volume I. Campinas, SP: Pontes Editores, 2011. p. 17-30.

NEGUERUELA-AZAROLA, E. Beliefs as conceptualizing activity: A dialectical approach for the second language classroom. System, v. 39, p. 359-369, 2011.

PASSARELLI, L.G. Da formação inicial à formação continuada: reflexões a partir da experiência da PUCSP. In: GIL, G.; VIEIRA-ABRAHÃO, M.H. (Org.). Educação de professores de línguas: os desafios do formador. Campinas: Pontes, 2008, p. 219-237.

PESSOA, R. R. Formação crítica de professores de línguas estrangeiras. In: SILVA, K. A. da et al (Org.). A formação de professores de línguas: novos olhares - volume I. Campinas, SP: Pontes Editores, 2011. p. 31-47.

SAITO, F. S.; SOUZA, P. N. de. (Multi)letramento(s) digital(is): por uma revisão de literatura crítica. Linguagens e Diálogos, v. 2, n. 1, 2011. p. 109-143.

SCHÖN, D.A. The reflective practitioner: how professionals think in action. Basic Books, 1983.

SILVA, K.A. Crenças no ensino-aprendizagem e na formação de professores de línguas: pontos e contrapontos. In: Crenças, discursos \& linguagem. Volume 2. Campinas: Pontes Editores, 2011, p. 23-61.

STURM, L. A pesquisa-ação e a formação teórico-crítica de professores de línguas estrangeiras. In: GIL, G.; VIEIRA-ABRAHÃO, M.H. (Org.). Educação de professores de línguas: os desafios do formador. Campinas: Pontes, 2008, p. 339-350.

URZÊDA-FREITAS, M. T. Educando para transgredir: reflexões sobre o ensino crítico de línguas estrangeiras/inglês. Trabalhos em Linguística Aplicada, Campinas, v. 1, n. 51, p. 77-98, jan./jun., 2012.

WARE, P.; LIAW. M.; WARSCHAUER, M. The Use of Digital Media in Teaching English as an International Language. In: AlSAGOFF, L. (Ed.). Principles and Practices for Teaching English as an International Language. New York: Routledge, 2012, p.67-84.

WARSCHAUER, M.; WHITTAKER, P. F. The Internet for English Teaching: Guidelines for Teachers. In: RICHARDS, J.C.; RENANDYA, W.A. Methodology in Language Teaching. Cambridge: Cambridge University Press, 2002, p. 368373. 